\title{
Antes de la Corte Electoral: Judicatura y elecciones en Uruguay (1825-1924)
}

\author{
Alexandre de Oliveira Bazilio de Souza ${ }^{1}$ \\ Universidade Federal do Espírito Santo, Brasil
}

Recibido: 25/03/2016

Aceptado: 22/05/2016

\begin{abstract}
Resumen. La creación de la Corte Electoral de Uruguay en 1924 es considerada por historiadores y contemporáneos un marco clave en la historia política de este país. El evento formó parte de una tendencia de la época, que defendía la especialización de los órganos electorales. El caso uruguayo es interesante porque la Corte Electoral allí creada no fue incluida en el Poder Judicial, como sucedió en otros países. La presencia de los jueces en la gestión del sufragio, sin embargo, fue una realidad en Uruguay antes del establecimiento de la Corte y ya aparecía desde los primeros reglamentos electorales del país. Este trabajo busca recorrer ese camino, con el fin de aclarar los sentidos y límites de esa peculiar atribución que recibió la Judicatura, principalmente en lo que se refiere a sus efectos para la construcción de la ciudadanía uruguaya.
\end{abstract}

Palabras claves: Corte Electoral; Judicatura; Elecciones; Uruguay

\begin{abstract}
The implementation of the Electoral Court in Uruguay in 1924 is considered, both by historians and contemporaries, a key event in the country's political history. The episode formed part of a tendency at the time which advocated for the specialization of the electoral organs. The Uruguayan experience is interesting because the Electoral Court created there was not inserted into the Judicial Power, as it was in other countries. The presence of judges in the electoral management, nevertheless, actually took place in Uruguay before the establishment of the Court, as it can be seen as early as in Uruguayan first electoral laws. This article examines this phenomenon, in order to understand the meanings and limits of this peculiar task assigned to the Judicial Power, particularly in terms of the effects it had on the construction of the country's citizenship.
\end{abstract}

Keywords: Electoral Court; Judicial Power; Elections; Uruguay

\footnotetext{
${ }^{1}$ Becario CAPES proceso ${ }^{\circ}$ BEX 6108/14-8. Doctorando en Historia y funcionario público en la Universidade Federal do Espírito Santo (UFES-Brasil).
} 


\section{Introducción}

A partir del siglo XIX se vio en Iberoamérica la amplia adopción de las elecciones como mecanismo para legitimar el poder estatal y designar los ocupantes de cargos públicos. ${ }^{2}$ Su práctica, no obstante, recibió muchas críticas de los contemporáneos, principalmente por el fraude, retórica frecuentemente repetida por gran parte de la historiografía, que concluyó que el sufragio en la región no se había desarrollado propiamente. 3

En la década de 1990, por otro lado, con la reciente salida de las dictaduras y la lucha por la consolidación de las democracias, nuevos objetos y corrientes teóricas fueron incorporados al estudio de las elecciones, que pasaron a ser vistas como un desdoblamiento de la ciudadanía. ${ }^{4}$ Era el resultado, entre otros factores, de la expansión de ese concepto a partir del abordaje marshalliano, según el cual habría tres especies de derechos (civiles, políticos y sociales), histórica y progresivamente creados. Su modelo fue incorporado en numerosas investigaciones, aunque de forma bastante crítica. 5 Asimismo, se empezaron a analizar los factores que influencian la proximidad de la población con las elecciones, según prescribe el esquema de Bryan Turner6. Al mirar la construcción de la ciudadanía a partir de dos ejes -dirección y espacio-, el autor afirma que ella podría suceder en escenarios muy distintos. El primer eje en ese sentido es interesante, porque indica que en muchos países la ciudadanía se desarrolló por iniciativa estatal y no de la población. Pese a ello, muchos investigadores suelen fijarse sólo en los fenómenos que tienen lugar por demanda popular, pues toman como modelo el caso francés, en que el individuo se afirmó frente al Estado.

José Murilo de Carvalho7 señala que en Brasil la participación ciudadana fue fruto de una emanación estatal, interpretación que creo podría extenderse también a

\footnotetext{
2 BRAGONI, Beatriz, "Los avatares de la representación. Sufragio, política y elecciones en Mendoza, 1854-1881", Hilda SABATO y Alberto LETTIERI (comp.), La vida política en la Argentina del siglo XIX. Armas, votos y voces, Buenos Aires, Fondo de Cultura Económica, 2003, p. 206.

3 ANNINO, Antonio, "Introducción", Antonio ANNINO (ed.) Historia de las elecciones en Iberoamérica. Siglo XIX, Buenos Aires, Fondo de Cultura Económica, 1995.

4 CAETANO, Gerardo, La República Batlista, Montevideo, Ediciones de la Banda Oriental, 2011, pp. 19-20.

5 MARSHALL, T. H., Ciudadanía y Clase Social, Madrid, Alianza, 1998; SABATO, Hilda, "Introducción", Hilda SABATO (coord.), Ciudadanía Política y Formación de las Naciones. Perspectivas históricas de América Latina, México, Fondo de Cultura Económica, 1999.

6 TURNER, Bryan S., "Outline of a theory of citizenship", Sociology, vol. 24, núm. 2, 1990, pp.189-217.

7 CARVALHO, José Murilo de, "Cidadania: tipos e percursos", Estudos Históricos, Rio de Janeiro, núm. 18, 1996, p.340.
} 
otras experiencias latinoamericanas ya que, en lo que se refiere a las elecciones, fue el Estado que las promovió y administró, indicando las autoridades que debían conducirlas. ${ }^{8}$ Aunque inicialmente esas autoridades tuvieron origen principalmente popular, a lo largo del siglo XIX fueron los funcionarios estatales, especialmente los jueces letrados, quienes desempeñaron esas tareas, proceso que culminaría con la aparición de las cortes electorales en el siglo siguiente.

Ese proceso, aunque con peculiaridades, tuvo lugar en diversos países. 9 En este trabajo analizo la presencia de los jueces en la gestión del sufragio en Uruguay. Como objetivo, busco explicar de qué manera el Poder Judicial ha estado involucrado con el sufragio. Utilizo como fuentes la legislación y los diarios de sesiones parlamentarias correspondientes al período que va desde los primeros reglamentos electorales nacionales hasta el establecimiento de la Corte Electoral en 1924.

\section{Debate historiográfico}

En la historiografía clásica de Uruguay las elecciones del siglo XIX son caracterizadas principalmente por sus elementos negativos. Cito en ese sentido la obra de Juan Pivel Devoto ${ }^{10}$, incisiva al describir que el fenómeno electoral uruguayo de la época estuvo marcado por el fraude, la violencia y la baja participación de los electores. Recién para el período que se abre en los años 1870 el autor señala con alguna claridad aspectos positivos en este campo, como las reformas en el Registro Cívico o las discusiones sobre la representación proporcional.

La historiografía más reciente no cuestiona esa interpretación y en gran medida se apoya en ella para defender la idea de que la democracia en Uruguay aparece recién en el siglo XX. Göran Lindahl ${ }^{11}$ afirma categóricamente que en la década de 1920 se alcanzó en Uruguay la verdad electoral, con la eliminación de cualquier tipo de fraude en las elecciones. Milton I. Vanger ${ }^{12}$, en relación con la reforma de 1916, escribe que "el corazón del proyecto fue la pureza electoral", en una

\footnotetext{
${ }^{8}$ SÁNCHEZ GÓMEZ, Gonzalo, "Ciudadanía sin democracia o con democracia virtual", Hilda SABATO, (coord.), Ciudadanía política..., ob. cit., p.435.

9 CABRAL, João Crisóstomo da Rocha, Sistemas eleitorais do ponto de vista da representação proporcional das minorias, Rio de Janeiro, Livraria Francisco Alves, 1929, pp.53-196.

${ }_{10}$ PIVEL DEVOTO, Juan, Historia de los Partidos Políticos en el Uruguay, Montevideo, Claudio García \& Cía., 1942-1943, 2 tomos.

${ }^{11}$ LINDAHL, Göran, Batlle: fundador de la democracia en el Uruguay, Montevideo, Editorial Arca, 1960, p.445.

12 VANGER, Milton I, José Batlle y Ordóñez (1915-1917): humanizando el capitalismo, Montevideo, Ediciones de la Banda Oriental, 2009, p.161.
} 
probable reproducción acrítica del discurso contemporáneo. Otros autores traen elementos nuevos al debate, aunque no modifiquen su contenido original. José Pedro Barrán y Benjamín Nahum ${ }^{13}$ sostienen que la democracia uruguaya aparece en las elecciones de la Asamblea Constituyente de 1916 con la concurrencia de tres factores: la expansión del electorado, la influencia de los comicios en la sociedad y la aceptación de la derrota por parte del Gobierno. Gerardo Caetano ${ }^{14}$, además de la ampliación del electorado, añade la expansión de la ciudadanía en el período por el establecimiento de políticas sociales integradoras, promovidas por el batllismo. Carlos Zubillaga ${ }^{15}$, por otro lado, no está de acuerdo con esa interpretación y declara que las primeras décadas del siglo $\mathrm{XX}$ no testimoniaron el surgimiento de una democracia en el país, sino la continuación de la lógica de restricción política del siglo anterior.

Ese conjunto de estudios promovió un avance fundamental en la historiografía del país al explorar las nuevas prácticas que se construyeron en el siglo XX. Por otro lado, a partir de una visión evolucionista, fue responsable de la consolidación de la idea de que antes de ese período el sufragio no había llegado a una etapa de madurez, desestimulando la investigación más profunda acerca de las elecciones en el siglo XIX. ${ }^{16}$ Ello no quiere decir que ciertas características atribuidas a esas prácticas no sean ciertas, pero sólo que no lo dicen todo, conforme señalan algunos historiadores. Eduardo Posada-Carbó ${ }^{17}$, por ejemplo, aunque caracteriza las elecciones del siglo XIX como pre-modernas o pre-democráticas -en el sentido de que había baja participación y falta de libertad de voto-, reconoce que gran parte de la historiografía

\footnotetext{
13 BARRAN, José Pedro, NAHUM, Benjamín, Batlle, los Estancieros y el Imperio Británico: la derrota del Batllismo (1916), Tomo 8, Montevideo, Ediciones de la Banda Oriental, 1987, p.8.

14 CAETANO, Gerardo, ob. cit., p.20.

15 ZUBILLAGA, Carlos, "El difícil camino de la participación política. Población, ciudadanía y electorado (1898-1918)”, Fernando J. DEVOTO y Marcela P. FERRARI, (comp.), La Construcción de las Democracias Rioplatenses: proyectos institucionales y prácticas políticas (1900-1930), Buenos Aires, Biblos, 1994, p.32 y 50. Según el autor, la Constitución de 1830 consagró un sistema altamente excluyente de la ciudadanía y el contexto político del siglo XIX se caracterizó por el fraude electoral, la coacción del Gobierno sobre los ciudadanos y la marginación de la ciudadanía. Zubillaga extiende esa interpretación para comienzos del siglo XX, pues cree que, a pesar de los esfuerzos de los sectores políticos para la mejora social de la vida del pueblo, no hubo ningún intento eficaz para aumentar y asegurar la participación ciudadana.

16 Una crítica a esa visión evolucionista del sufragio se encuentra en ANNINO, Antonio, "El voto y el XIX desconocido", Istor, núm. 17, 2004, pp.43-59 y ROMANELLI, Raffaele, "Sistemas electorales y estructuras sociales. El siglo XIX europeo", Salvador FORNER (coord.), Democracia, elecciones y modernización en Europa. Siglos XIX y XX, Madrid, Cátedra, 1997.

${ }_{17}$ POSADA-CARBÓ, Eduardo, "Elections before Democracy. Some considerations on electoral history from a comparative approach", E. POSADA-CARBÓ, Elections before Democracy. The history of elections in Europe and Latin America, Houndmills, Macmillan Press Ltd, 1996, pp.2-4.
} 
no se dio cuenta de que ese proceso electoral tenía una lógica propia. Hilda Sabato ${ }^{18}$ explica que la visión que enfatiza la distancia entre los parámetros liberales y las prácticas electorales deduce, a partir de la baja participación, el igual bajo interés de la población en los asuntos políticos o, al menos, su marginación; y, a partir de la manipulación de las elecciones, la falta de legitimidad de ese proceso. En consecuencia, esos estudios no se preguntan sobre el sistema político que de hecho existía, ya que consideran toda experiencia electoral previa a las primeras décadas del siglo XX como un gran bloque homogéneo. Marcela Ternavasio ${ }^{19}$ apunta que en la historiografía latinoamericana el fraude ha sido usado como clave explicativa de los procesos de representación, reduciendo el estudio del sufragio al que teleológicamente debería ser. Personalmente, yo agregaría aun a esas críticas la ausencia de problematización acerca del Derecho Procesal Electoral en esos trabajos, ya que asumen que sólo los elementos sustanciales de los fenómenos jurídicos son relevantes en la investigación sobre la ciudadanía.

Por lo tanto, no es sorprendente que la historiografía uruguaya no trate largamente sobre la administración judicial de las elecciones, especialmente la del siglo XIX. Como explica Ezequiel Gallo ${ }^{20}$, en la historia política rioplatense hay un énfasis en las instituciones del Poder Ejecutivo y poco se estudia el Poder Judicial, incluso el Electoral. ${ }^{21}$ Ello sucede, en mi opinión, porque se hace hincapié en la organización partidaria del país como factor de explicación de los cambios en su estructura electoral, los que serían así productos de acuerdos para la resolución de los

\footnotetext{
${ }^{18}$ SABATO, Hilda, La política en las calles: entre el voto y la movilización (Buenos Aires, 1862-1880), Buenos Aires, Sudamericana, 1998, pp.12-15.

19 TERNAVASIO, Marcela, La Revolución del Voto. Política y Elecciones en Buenos Aires (1810-1852), Buenos Aires, Siglo XXI, 2002, pp.17-18.

${ }^{20}$ GALLO, Ezequiel, "Prólogo", Fernando J. DEVOTO, Marcela P. FERRARI, (comp.), La Construcción... op. cit., p.13.

${ }^{21}$ La excepción más significativa sea quizás la de Pivel Devoto, quien hace numerosas incursiones a los debates sobre la gestión judicial de las elecciones y parece incluso posicionarse contra esa y en favor de la gestión popular. El autor afirma que la Ley de 27 de abril de 1878 "incorporaba a su articulado una reforma fundamental en la constitución de las mesas electorales, que se organizarían desde entonces con absoluta prescindencia de la administración de la Justicia, elegidas por las Juntas E. Administrativas, [...] y mediante la cual se daba al pueblo una intervención directa en tales actos". Diez de Medina también llega a hacer frente a la gestión de los jueces, pero de forma más breve y menos crítica. Consultar PIVEL DEVOTO, Juan, ob. cit., tomo 1, pp.276-279 y 284-285, tomo 2, pp.77, 84, 90, 218-219 y 233-234 y DIEZ DE MEDINA, Álvaro, Historia Electoral del Uruguay (1810-1910), Montevideo, Fundación de Cultura Universitaria, 1994, pp.225 y 336. La discusión sobre la estructura electoral y especialmente la presencia de la Judicatura en ella tampoco aparece en la historiografía argentina consultada. Para otros países, principalmente de Latinoamérica y Europa, consultar: CABRAL, João Crisóstomo da Rocha, ob. cit.; GROS ESPIELL, Héctor, La Corte Electoral del Uruguay, San José, CAPEL, 1990; OROZCO HENRIQUEZ, J. Jesús, "El contencioso electoral, la calificación electoral", NOHLEN, Dieter et al, Tratado de derecho electoral comparado de América Latina, Ciudad del México, Fondo de Cultura Económica, 2007.
} 
conflictos políticos. Sin embargo, no se nota una correlación entre la filiación partidaria y la opinión con respecto a la administración judicial de las elecciones, como discuto más adelante. Asimismo, al comparar el escenario uruguayo con el de otros países -muchos de los cuales no tenían esa actuación partidaria bien delimitada-, se notan numerosas similitudes con sus reformas electorales en el período. ${ }^{22}$ La influencia de esos modelos extranjeros aparece tanto en citas en los diarios de sesiones del Poder Legislativo como en la presencia de Uruguay en arenas internacionales de discusión acerca del sufragio, tema que también abordo. Sin tener en consideración esos y otros factores, se acabó por enaltecer la legislación de 19241925 propuesta por una comisión integrada por miembros de todos los partidos representados en el Parlamento, que crearía la Corte Electoral, relacionando ese evento con el fin del fraude electoral en el país. ${ }^{23}$

\section{La legislación}

Las normas legislativas sobre las autoridades electorales en el período estudiado fueron numerosas y complejas. Diferentes actores fueron siendo incorporados en esa estructura para que desempeñaran las distintas actividades relacionadas con la gestión del sufragio. Para facilitar la comprensión de esos cambios, la Tabla 1 muestra por año y tipo de actividad asignada cuáles eran las autoridades encargadas de la elección para representantes. A continuación, la legislación es discutida en forma más detallada.

\footnotetext{
${ }^{22}$ SOUZA, Alexandre de Oliveira Bazilio de, Das urnas para as urnas: juízes de paz e eleições no Espírito Santo (1871-1889), Saarbrücken, Novas Edições Acadêmicas, 2013.

${ }_{23}$ Lindahl, por ejemplo, caracteriza la Corte Electoral como un organismo especial y administrativamente independiente, que se convirtió, en sus palabras, en "la piedra angular de la democracia uruguaya”. Consultar LINDAHL, Göran, ob. cit., p.133. Consultar también CUADRO CAWEN, Inés, "Partidos, elecciones y democracia política", Ana FREGA et al., Historia del Uruguay en el siglo XX (1890-2005), Montevideo, Ediciones de la Banda Oriental, 2007, pp.325-326.
} 
Tabla 1

Administradores electorales en Uruguay. Elecciones para representantes (1825-1924)

\begin{tabular}{|c|c|c|c|c|c|}
\hline Año & Inscripción & Votación & $\begin{array}{l}\text { Secretarios y } \\
\text { escrutadores }\end{array}$ & $\begin{array}{c}\text { Escrutinio } \\
\text { General }\end{array}$ & Validación \\
\hline $1825^{24}$ & No hay & $\begin{array}{l}\text { Autoridad } \\
\text { judicial del } \\
\text { pueblo y el } \\
\text { párroco o su } \\
\text { vice }\end{array}$ & $\begin{array}{l}\text { Nombrados por } \\
\text { los miembros de } \\
\text { la mesa }\end{array}$ & $\begin{array}{l}\text { Secretario y } \\
\text { escrutadores }\end{array}$ & No especificado \\
\hline $1830^{25}$ & $\begin{array}{c}\text { Juez de paz (JP) } \\
\text { auxiliado por los } \\
\text { tenientes alcaldes (TA) } \\
\text { respectivos }\end{array}$ & $\begin{array}{l}\text { JP y cuatro } \\
\text { ciudadanos } \\
\text { sacados a la } \\
\text { suerte }\end{array}$ & $\begin{array}{c}\text { Nombrados por y } \\
\text { entre los } \\
\text { miembros de la } \\
\text { mesa }\end{array}$ & $\begin{array}{c}\text { Alcalde } \\
\text { ordinario }{ }^{26}, \text { seis } \\
\text { ciudadanos, el } \\
\text { defensor y un } \\
\text { JP del pueblo } \\
\end{array}$ & $\begin{array}{c}\text { Cámara de } \\
\text { Representantes }\end{array}$ \\
\hline $1874^{27}$ & $\begin{array}{c}\text { Comisión Inscriptora } \\
\text { (CI) formada por el JP } \\
\text { y cuatro miembros } \\
\text { elegidos por las Juntas } \\
\text { Económico- } \\
\text { Administrativas (JEA), } \\
\text { con recurso a un jurado } \\
\text { de ocho ciudadanos } \\
\text { elegidos por la JEA y } \\
\text { presidido por el JP }\end{array}$ & $\begin{array}{l}\text { JP y cuatro } \\
\text { ciudadanos } \\
\text { sacados a la } \\
\text { suerte }\end{array}$ & $\begin{array}{l}\text { Nombrados por y } \\
\text { entre los } \\
\text { miembros de la } \\
\text { mesa }\end{array}$ & $\begin{array}{c}\text { Alcalde } \\
\text { ordinario, seis } \\
\text { ciudadanos } \\
\text { sacados a } \\
\text { suerte, el } \\
\text { defensor y un } \\
\text { JP del pueblo }\end{array}$ & $\begin{array}{c}\text { Cámara de } \\
\text { Representantes }\end{array}$ \\
\hline $1878^{28}$ & $\begin{array}{l}\text { CI formada por cinco } \\
\text { miembros elegidos por } \\
\text { las JEA, con recurso a } \\
\text { un Jurado de cinco } \\
\text { ciudadanos elegidos de } \\
\text { la misma forma }\end{array}$ & $\begin{array}{c}\text { Comisión } \\
\text { Receptora (CR) } \\
\text { compuesta por } \\
\text { cinco titulares } \\
\text { elegidos JEA }\end{array}$ & No especificado & $\begin{array}{c}\text { Comisión } \\
\text { Escrutadora } \\
\text { (CE) formada } \\
\text { por el } \\
\text { presidente de la } \\
\text { JEA y ocho } \\
\text { ciudadanos }\end{array}$ & $\begin{array}{c}\text { Cámara de } \\
\text { Representantes }\end{array}$ \\
\hline $1887^{29}$ & $\begin{array}{l}\text { CI formada por cinco } \\
\text { miembros elegidos por } \\
\text { las Juntas Electorales } \\
\text { (JE), con recurso a un } \\
\text { Jurado de cuatro } \\
\text { ciudadanos y presidido } \\
\text { por el JP }\end{array}$ & $\begin{array}{c}\text { Mesa } \\
\text { compuesta por } \\
\text { ciudadanos } \\
\text { sorteados, } \\
\text { presidida por el } \\
\text { JP o vocal } \\
\text { elegido por los } \\
\text { miembros de la } \\
\text { mesa } \\
\end{array}$ & No especificado & $\begin{array}{l}\text { CE formada por } \\
\text { el presidente de } \\
\text { JEA y ocho } \\
\text { ciudadanos }\end{array}$ & $\begin{array}{c}\text { Cámara de } \\
\text { Representantes }\end{array}$ \\
\hline
\end{tabular}

24 Instrucciones de Junio 17 de 1825 (artículos $4^{\circ}$ y $8^{\circ}$ ).

25 Decreto de Marzo 30 de 1830 (artículos $4^{\circ}, 9^{\circ}, 11^{\circ}$ y $18^{\circ}$ ).

${ }^{26}$ En los pueblos cabeza de departamento donde no había alcalde ordinario haría sus veces el presidente de la Junta Económico-Administrativa (Ley $n^{0} 324 / 1853$, art. 12).

${ }^{27}$ Ley $\mathrm{n}^{0} 1.234 / 1874$.

${ }^{28}$ Ley n $^{0} 1.392 / 1878$ (artículos $3^{\circ}$ y 15 ).

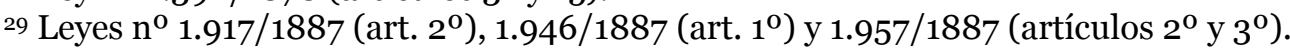




\begin{tabular}{|c|c|c|c|c|c|}
\hline $1893^{30}$ & $\begin{array}{l}\text { CI formada por cinco } \\
\text { miembros sorteados } \\
\text { por las JE, con } \\
\text { apelación a la JE y ante } \\
\text { el Superior Tribunal de } \\
\text { Justicia }\end{array}$ & $\begin{array}{l}\text { CR compuesta } \\
\text { de cinco } \\
\text { ciudadanos, } \\
\text { sorteados por } \\
\text { la JE }\end{array}$ & $\begin{array}{c}\text { Secretario } \\
\text { nombrado por la } \\
\text { CR }\end{array}$ & JE & $\begin{array}{c}\text { Cámara de } \\
\text { Representantes }\end{array}$ \\
\hline $1898^{31}$ & $\begin{array}{c}\text { CI formada por cinco } \\
\text { miembros elegidos por } \\
\text { las JE, con reclamo a la } \\
\text { Comisión Calificadora } \\
\text { (CC) } 3^{2} \text { y apelación ante } \\
\text { la JE y el Tribunal } \\
\text { Pleno } \\
\end{array}$ & $\begin{array}{l}\text { CR compuesta } \\
\text { de cinco } \\
\text { ciudadanos, } \\
\text { elegidos por la } \\
\text { JE }\end{array}$ & $\begin{array}{c}\text { Secretario } \\
\text { nombrado por la } \\
\text { CR }\end{array}$ & JE & $\begin{array}{l}\text { Cámara de los } \\
\text { representantes }\end{array}$ \\
\hline $1915^{33}$ & $\begin{array}{l}\text { CI formada por tres } \\
\text { miembros elegidos por } \\
\text { las JE, con apelación } \\
\text { para ante la JE y la Alta } \\
\text { Corte de Justicia } \\
\text { (capital) o jueces } \\
\text { letrados (demás } \\
\text { departamentos) } \\
\end{array}$ & $\begin{array}{l}\text { CR compuesta } \\
\text { de tres } \\
\text { miembros } \\
\text { elegidos por las } \\
\text { JE }\end{array}$ & No especificado & JE & $\begin{array}{l}\text { JE, con recurso a } \\
\text { la Alta Corte de } \\
\text { Justicia (capital) o } \\
\text { juez letrado } \\
\text { (demás } \\
\text { departamentos) }\end{array}$ \\
\hline $1924^{34}$ & $\begin{array}{l}\text { Oficina inscriptora } 35, \\
\text { con recurso a las JE y la } \\
\text { Corte Electoral }\end{array}$ & $\begin{array}{l}\text { CR compuesta } \\
\text { por tres } \\
\text { miembros } \\
\text { elegidos por las } \\
\text { JE }\end{array}$ & $\begin{array}{l}\text { Miembro de la CR } \\
\text { que recibió más } \\
\text { votos después del } \\
\text { presidente }\end{array}$ & JE & $\begin{array}{c}\text { JE, con apelación } \\
\text { a la Corte } \\
\text { Electoral }\end{array}$ \\
\hline
\end{tabular}

Fuente: ARMAND UGÓN, E. et al, Compilación de Leyes y Decretos (1825-1930), Montevideo, ROU, 1930, varios tomos.

La primera norma electoral creada por orientales fue resultado de la revolución conducida por Juan Antonio Lavalleja y Manuel Oribe en 1825, conocida como Cruzada Libertadora. El Gobierno Provisorio de la Provincia Oriental convocó el 17 de junio de aquel año a los pueblos para elegir representantes para constituir una asamblea (la Sala de Representantes) en la villa de Florida, fijando los procedimientos a seguir. ${ }^{36}$ Como era común en la época, el texto tenía una fuerte

\footnotetext{
$3^{30}$ Leyes $\mathrm{n}^{\mathrm{o}} 2.221 / 1893$ (artículos $5^{\mathrm{o}}, 11,12$ y 41) y 2.224/1893 (artículos $4^{\mathrm{o}}, 7^{\mathrm{o}}, 10$ y 26 ).

${ }^{31}$ Leyes $\mathrm{n}^{0} 2.527 / 1898$ (artículos $^{\circ}, 11,12,17,23,31,42$ y 53) y 2.563/1898 (artículos $5^{\circ}, 6^{\circ}, 9^{\circ}, 24$ y $35)$.

${ }^{32}$ Comisión Calificadora constituida a partir de la exclusión, por sorteo, de tres miembros de la Comisión Inscriptora, sustituidos por sus suplentes. A partir de la ley ${ }^{\circ}{ }_{2.555 / 1898}$ (art. $2^{\circ}$ ), pasaron a ser elegidas de la misma forma que las Comisiones Inscriptoras.

33 Convención Nacional Constituyente. Leyes $\mathrm{n}^{0}$ 4.282/1912 (art. $3^{\circ}$ ) y 5.332/1915 (artículos 14, 16, 26, $39,48$ y 49$)$.

${ }_{34}$ Leyes no $7.690 / 1924$ (artículos 4 $4^{\circ}, 12$ "c", 16, 30 "Ch" y "f", 50, 52 "a", 54, 55, 76 y 109) y 7.812/1925 (artículos $2^{\circ}, 26,32,36,61,125,141,158$ y 160).

35 Compuestas de un jefe, uno o más auxiliares. Las oficinas electorales departamentales podrían tener dicha función o delegarlas a oficinas inscriptoras delegadas.

${ }^{36}$ ACEVEDO, Eduardo, Anales Históricos del Uruguay, Montevideo, Barreiro y Ramos, 1933, tomo 1, pp.293-294. DIEZ DE MEDINA, Álvaro, ob. cit., p.65. GONZÁLEZ, Rodolfo, Legislación Electoral del Uruguay (Tomo I -1730 -1903), [s.l.], Celadu, 1991, p.36.
} 
inspiración en Cádiz tanto para definir quién compondría el electorado37, como para designar los administradores del sufragio. Estos serían así la autoridad judicial del pueblo ${ }^{38}$ y el cura párroco, que presidirían la mesa electoral. No había ningún registro previo de electores y la elección tenía dos grados, realizada en actos continuos. Esos dos administradores tenían prácticamente todo el control del proceso electoral de entonces.

En el contexto de la Independencia, el gobernador delegado, Luis Eduardo Pérez, emitió el Decreto de 26 de julio de 1828, que mantenía, con pequeños cambios con respecto a la cantidad de diputados, las normas establecidas tres años antes. Así, el 17 de agosto de aquel año se llevaron a cabo las elecciones para la Asamblea Constituyente, instalada tres meses más tarde. En su seno se elaboró la nueva ley electoral. El proyecto, presentado el 19 de febrero de 1830, fue aprobado el 29 de marzo y sancionado el 1 de abril.

El texto, que estuvo en vigencia sin modificaciones importantes por más de cuarenta años, cambió la estructura inicial de la administración electoral. En primer lugar, porque eliminó al párroco y los jueces coloniales, en consonancia con los cambios en la organización judicial del país. 39 En lugar de ellos, al menos seis nuevos actores fueron introducidos como gestores electorales, entre los cuales el alcalde ordinario y el juez de paz ganaron más prominencia. Este último, cuyo cargo fue

\footnotetext{
37 El texto oriental permitió el voto para los mayores de 20 años, con excepción de los esclavos, según las Instrucciones de 17 de junio de 1825 (art. $3^{\circ}$ ).

${ }^{38} \mathrm{La}$ autoridad judicial referida probablemente era el alcalde ordinario. Al menos así sucedió en la villa de San Juan Bautista, en las elecciones para diputado en 1825 , organizadas por el alcalde ordinario José Cubero, conjuntamente con el párroco y los jueces comisionados de la villa. Consultar DE LOS SANTOS, Clarel, De la soberanía provincial a la facción gobernante. Experiencias electorales en Villa San Juan Bautista-Canelones (1825-1838), Ponencia en VI Jornadas Académicas de la Facultad de Humanidades y Ciencias de la Educación, Montevideo, 2015.

39 La estructura judicial colonial tenía como base los Cabildos. En 1826, por medio de la ley de 6 de octubre, fueron suprimidos y las funciones judiciales de los alcaldes ordinarios pasaron a los jueces letrados, creados por la misma norma, así como lo fueron los jueces de paz y el Tribunal de Apelaciones. En 1827, el decreto de 6 de diciembre estableció que los alcaldes desempeñarían otra vez sus funciones judiciales, eliminando así los jueces letrados. Asimismo, fueron eliminados los jueces de paz y los tenientes alcaldes, sustituidos por jueces subalternos, nombrados por el alcalde. El decreto, no obstante, fue derogado por el Reglamento Provisorio de Administración de Justicia de agosto de 1829, que restableció gran parte la legislación anterior -aunque mantuvo los alcaldes ordinarios- y quedaría en vigencia, con modificaciones puntuales, hasta la publicación del Código de Procedimiento Civil de 1878. Según Cuadro, el decreto que suprimió los jueces letrados y de paz representó una tentativa del gobierno que disolvió la Sala de Representantes por revivir antiguas prácticas políticas de tradición popular, principalmente el mantenimiento de ciertos poderes locales, aunque no se hubiera optado por el restablecimiento de los Cabildos. Consultar CUADRO CAWEN, Inés, "La crisis de los poderes locales. La construcción de una nueva estructura de poder institucional en la Provincia Oriental durante la guerra de independencia contra el Imperio del Brasil (1825-1828)", Ana FREGA, Historia Regional e Independencia del Uruguay. Proceso histórico y revisión crítica de sus relatos, Montevideo, Ediciones de la Banda Oriental, 2009, pp.96-97.
} 
creado en 1826, tendría el rol de juez, árbitro y conciliador, actuando siempre verbalmente. Así como ocurrió con sus homólogos de otros países, el puesto fue inicialmente pensado para hacerse cargo de las demandas civiles de menor valor, con pequeñas incursiones en materia penal o policial. ${ }^{\circ 0} \mathrm{Su}$ forma de investidura inicial era por designación de los tenientes alcaldes reunidos. Estos eran auxiliares del juez de paz, elegidos directamente por la ciudadanía, como también lo eran los alcaldes ordinarios, autoridades de escalón más alto que funcionaban en la villa cabeza del departamento y juzgaban recursos de sentencias del juez de paz u originalmente procesos arriba de ese ámbito de competencia. A partir de 1829, fueron los alcaldes ordinarios suplentes quienes, al lado de cuatro vecinos de la villa cabeza del departamento, administrarían la elección del titular del cargo, así como lo harían los suplentes de los tenientes alcaldes para sus titulares..$^{41}$

En el ámbito electoral, el juez de paz actuaría en dos etapas del proceso: la inscripción de los electores en el Registro Cívico ${ }^{42}$ creado por la nueva ley, y la votación, como presidente de la mesa. Excepción a esa formación se produjo sólo en el Colegio de Senadores, presidido y auxiliado por miembros designados por el alcalde ordinario. Fue este funcionario también quien se convirtió en responsable de la realización del escrutinio general en la Mesa Central de la villa cabeza del departamento. Por último, también participarían en la gestión electoral los representantes y senadores, que validarían las elecciones de sus propios cargos, conforme disposición constitucional: tras el escrutinio, los documentos electorales eran enviados a la respectiva Cámara legislativa, donde se formarían comisiones para analizarlos y emitir un informe que se sometería a votación en el cuerpo.43

\footnotetext{
40 Consultar nota precedente sobre administración de la Justicia, reglamento de 26 de enero de 1827 y SOUZA, Alexandre de Oliveira Bazilio de, ob. cit.

${ }_{41}$ Antes del Reglamento de 1829, la elección de los alcaldes ordinarios era indirecta y el Gobierno elegía entre los tres primeros más votados. Consultar el Decreto de 6 de diciembre, 1827 (artículos $1^{\circ}$, $2^{\mathrm{o}}$ y $7^{\circ}$ ) y el Reglamento Provisorio de la Administración de la Justicia de 10 de agosto 1829 (artículos $7^{\circ}, 10^{\circ}$ y 70$)$.

$4^{2}$ Algunos autores señalan que el Registro Cívico fue creado posteriormente. Héctor Gros Espiell, Juan José Arteaga y Carlos Zubillaga indican la Ley de 14 de julio de 1858. Juan E. Pivel Devoto y Alcira Ranieri de Pivel señalan la Ley de 18 de junio de 1858. Como se muestra, sin embargo, un registro cívico ya existía desde 1830, aunque no tenía carácter permanente. En 1853, por otro lado, se creó una ley que lo reguló. Consultar el Decreto de 30 de marzo 1830 (artículos $3^{\circ}, 4^{\circ}$ y $5^{\circ}$ ); la Ley ${ }^{\circ} 324$ de 16 de junio de 1853; GROS ESPIELL, Héctor, ARTEAGA, Juan José, Esquema de la Evolución Constitucional del Uruguay, Montevideo, Fundación de Cultura Universitaria, 1991, pp.53-54; ZUBILLAGA, Carlos, ob. cit., p.33 y PIVEL DEVOTO, Juan E., RANIERI DE PIVEL, Alcira, ob. cit., p.466.

43 Decreto de 30 de marzo de 1830 (artículos $3^{\circ}, 4^{\circ}, 5^{\circ}, 9^{\circ}, 18$ y 35), Constitución de 1830 (art. 43) y GROS ESPIELL, Héctor, ob. cit., pp.61-99.
} 
La inclusión de nuevos administradores electorales en el país se produjo en la segunda mitad del siglo XIX. En las elecciones para alcalde ordinario, defensor de menores y teniente alcalde, el Superior Tribunal de Justicia pasó a ser responsable de la validación.44 Era una actividad restringida, pero de gran importancia, ya que por primera vez los jueces de carrera tenían una función electoral y en una fase que antes únicamente existía para las elecciones de parlamentarios. Se creaba así una tarea eminentemente judicial, cuando el tribunal debía juzgar reclamaciones presentadas a la mesa durante la votación.

Otro administrador incluido, esta vez de una manera más amplia, fue la Junta Económico-Administrativa. Estos eran órganos electivos creados por la Constitución, responsables de la administración de los departamentos. Primeramente, los poderes electorales otorgados consistían en indicar los ciudadanos responsables del Registro Cívico, ahora dividido en una comisión que realizaba el trabajo inicial y un Jurado, creado para recibir quejas sobre el procedimiento. Un poco más tarde, las Juntas también comenzaron a indicar los ciudadanos de las Comisiones Receptoras. En esta segunda etapa, el presidente de la Junta empezó a formar, conjuntamente con ocho ciudadanos, la Comisión Escrutadora, también establecida en ese momento.45

A partir de esas reformas se dio por terminada en gran medida la gestión electoral de los jueces legos, a excepción de las elecciones para tenientes alcaldes, en las que la Mesa Receptora era presidida por el teniente alcalde suplente, con la ayuda de dos residentes del distrito, designados por la Junta Económico-Administrativa. La misma legislación tornó electiva la Justicia de Paz; la Comisión Receptora en ese caso, sin embargo, no siguió las mismas reglas y adoptó la formación detallada en el párrafo anterior. Por otro lado, existía una similitud entre los dos procesos en la fase de validación: las quejas serían enviadas al juez letrado departamental, que las remitiría ex-officio al Superior Tribunal de Justicia. ${ }^{46}$

En ese momento, las Juntas Económico-Administrativas eran el gestor que tenía más actividades electorales. Su importante rol en las elecciones uruguayas se extendió por veintiún años, hasta que sus funciones relacionadas con el sufragio

${ }^{44}$ Ley $\mathrm{n}^{\circ}$ 626/186o (art. 15). Decisión del Superior Tribunal de Justicia de 5 de febrero de 1861 (art. 12).

45 Consultar Constitución de 1830 (artículos 122-129) y leyes $\mathrm{n}^{\mathrm{O}} 1.234 / 1874$ (artículos $2^{\mathrm{o}}$ y 14 ) y $1.392 / 1878$ (artículos $3^{\circ}$ y 15 ).

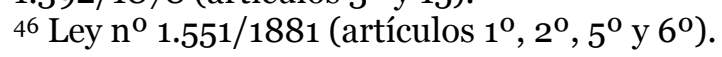


fueron trasladadas a las Juntas Electorales, creadas en 1887.47 Estas fueron el primer órgano del país dedicado exclusivamente a la gestión electoral. Eran predominantemente electivas, tenían un mandato de tres años y un número de miembros entre seis y nueve..$^{8}$ En sus primeros años de funcionamiento fueron responsables de la designación de los miembros de las Comisiones y Jurados de inscripción; pero, a partir de 1893, ya tenían operaciones en todas las fases electorales, con la única excepción de la validación. En la fase de inscripción, indicaban los miembros de la Comisión y pasaron a hacerlo también para la Comisión Receptora. En la votación en el colegio electoral de senadores, ahora era el presidente de la Junta Electoral quien proponía un presidente y un secretario.

Además de la organización de otros órganos, las Juntas Electorales empezaron ellas mismas a realizar directamente algunas funciones electorales, como juzgar los recursos presentados en el Registro Cívico y realizar el escrutinio general del departamento. En el primer caso, se estableció aún una segunda instancia, el Superior Tribunal de Justicia. Se fijaba así la presencia de jueces de carrera en la fase de inscripción -esta vez en las elecciones para todos los cargos, y no solamente para los del Poder Judicial. En 1898 se creó una instancia específica para recibir las quejas vinculadas al Registro Cívico antes de la apelación: la Comisión Calificadora.49 Ese mismo año se decidió que los Tribunales reunidos nombrarían los jueces de paz y los tenientes alcaldes, según había dispuesto el Código de Procedimiento Civil veinte años antes. $5^{0}$

En los siguientes veinticinco años esa fue la estructura electoral básica del país, con excepción de las normas específicas para la elección de la Convención Constituyente de 1916, donde la última instancia de los recursos sobre la inscripción sería la Alta Corte de Justicia, en Montevideo, y los jueces letrados, en el interior del país. Empezaba así la presencia de jueces de carrera de primera instancia en la gestión nacional de las elecciones. También entonces por primera vez no serían los

\footnotetext{
47 En 1887 se transfirieron las funciones relacionadas con el Registro Cívico. En 1893 todas sus funciones electorales pasaron a las Juntas Electorales. Consultar leyes $\mathrm{n}^{\mathrm{o}} 1.957 / 1887\left(\operatorname{artículos~} 1^{\mathrm{o}}, 2^{\mathrm{o}} \mathrm{y}\right.$ $3^{\circ}$ ) y $2.224 / 1893$ (artículos 26 y 39 ).

${ }^{48}$ Los datos se refieren al período de 1887 a 1924. En cuanto a la investidura por elección, la excepción se produjo durante la vigencia de las leyes $\mathrm{n}^{0} 2.221 / 1893$ y 2.224/1893, cuando serían parte de la Junta el presidente de la Junta Económico-Administrativa, el director general de impuestos directos, el Jefe Político, tres delegados del cuerpo legislativo y tres ciudadanos sacados a suerte.

49 Leyes $n^{0} 2.221 / 1893$ (artículos 11 y 41), 2.224/1893 (artículos $7^{\circ}, 26$ y 39) y 2.527/1898 (art. 31).

$5^{5}$ Ley $\mathrm{n}^{\mathrm{O}} 1.551 / 1881$ (artículo $1^{\mathrm{o}}$ ), Código de Procedimiento Civil de 1878 (artículo 89) y ley $\mathrm{n}^{\mathrm{o}}$ $2.529 / 1898\left(\operatorname{artículo~}^{\circ}\right)$.
} 
parlamentarios los responsables de la calificación final de las elecciones nacionales, sino la Junta Electoral, en primera instancia, con el recurso a los dos órganos judiciales citados. ${ }^{1}$

Por último, a partir de 1924, Uruguay estableció una estructura electoral marcada por dos órganos: la Junta Electoral y la Corte Electoral. La primera llevaría a cabo tareas en el ámbito local y departamental, directamente o a través de funcionarios designados o elegidos, en las etapas de inscripción, votación, escrutinio y validación de las elecciones. La segunda estaría integrada por siete miembros elegidos por la Asamblea General Legislativa y sería el órgano administrador general del sufragio, con atribuciones administrativas, legislativas y judiciales: administrar el Registro Cívico Nacional, nombrar a los funcionarios, llevar a cabo la votación para la elección del Consejo Nacional de Administración, crear las reglas para su propio funcionamiento y juzgar, en última instancia, los procesos electorales..$^{2}$

\section{Las discusiones en el Parlamento}

El panorama normativo presentado proporciona una visión general de cómo se implementó la gestión judicial de las elecciones en Uruguay. Sin embargo, hay elementos centrales que no pueden ser captados en ese tipo de fuente, que recoge los resultados finales en cada instancia, sin dar cuenta de la discusión ocurrida durante el proceso de elaboración de las normas. En ese sentido, es pertinente entender cómo sucedieron las discusiones que condujeron a esa legislación. Así, esta sección presenta los puntos principales planteados por los legisladores uruguayos durante esos debates, sus vicisitudes y las diferentes posiciones que adoptaron. En notas al pie, describo detalles de la carrera política de esos actores y su filiación partidaria, siempre que esté disponible.

Metodológicamente, la investigación siguió algunos pasos que debo aclarar. Los diarios de sesiones parlamentarias de Uruguay no están disponibles en formato digital, por lo que es difícil o casi imposible la producción de archivos en formato de texto, al menos para un investigador que trabaja de forma individual. Esta situación podría incluso inviabilizar una búsqueda con tan amplio marco temporal, de no contarse con la obra de E. Armand Ugón, J. C. Cerdeiras Alonso, L. Arcos Ferrand y

${ }^{51}$ Leyes $\mathrm{n}^{0} 4.282 / 1912$ (art. 17) y 5.332/1915 (artículos 36 y 49).

${ }^{2}$ Leyes no $7.690 / 1924$ (artículos $4^{\circ}, 12$ y 30) y 7.812/1925 (art. 144). 
C. Goldaracena53, quienes hicieron una recopilación de la legislación uruguaya indicando para cada ley sus referencias parlamentarias. De ese modo, fue posible buscar directamente las páginas de los diarios donde se encuentran las discusiones de las leyes electorales aprobadas. Es de orden aclarar que los proyectos que no se convirtieron en ley no fueron incluidos en esta primera pesquisa. Con el fin de minimizar el impacto que esa restricción podría representar al trabajo, se lo complementó, de manera limitada, con fuentes secundarias. Cinco fueron las colecciones de anales parlamentarios consultadas: Actas y Diarios de sesiones de la Cámara de Representantes, Diarios de sesiones de la Cámara de Senadores, Diarios de sesiones de la Asamblea General y Diarios de sesiones del Consejo de Estado.54 La franja temporal de la investigación empieza en 1830, cuando los registros parlamentarios están disponibles, y termina en 1925 con la ley de elecciones, complementaria a la del año anterior que creó la Corte Electoral.

La injerencia de los jueces en la gestión electoral fue, durante gran parte del siglo XIX, un problema poco mencionado en los anales parlamentarios. Ello sucedió, por un lado, porque la ley de 1830 tuvo una vigencia muy larga y, por otro, porque esas fuentes, para la primera mitad del siglo, están en formato de acta y no de versión taquigráfica. Hubo, no obstante, algunas excepciones a esa ausencia. Rodolfo González 55 cita un proyecto de 5 de mayo de 1836, presentado por José Ellauri56, para que los alcaldes ordinarios perdieran sus funciones electorales en favor de las Juntas Económico-administrativas. En 1853, se presentó un proyecto examinado por la Comisión de Legislación de la Asamblea General, que proponía asignar al Tribunal de Apelación la validación de las elecciones de tenientes alcaldes. El integrante de la Comisión, Cándido Juanicó57, dijo que hizo tal sugerencia porque constantemente eran enviadas consultas sobre la materia a las comisiones del Parlamento. 58

\footnotetext{
53 ARMAND UGÓN, E. et al, ob. cit., 1930.

54 Decreto de 10 de febrero de 1898. Fue resultado de un golpe de Estado conducido por el presidente Juan Lindolfo Cuestas, después de perder apoyo de la mayoría de la Asamblea. Consultar ACEVEDO, Eduardo, ob. cit., 1934, tomo 5, pp.121-125.

55 GONZÁLEZ, Rodolfo, ob. cit., p.41.

56 Diputado por Montevideo (1834-1837) y senador por Canelones (1830). Parlamentarios Uruguayos, [s.l.], Presidencia de la Asamblea General y del Senado, Presidencia de la Cámara de Representantes, 2006, p.587.

57 Diputado por Montevideo (1852-1854; 1858-1861). Parlamentarios..., ob. cit., p.746.

${ }_{58}^{8}$ Diario de Sesiones de la Honorable Asamblea General (De aquí en adelante AG), 03/07/1853, tomo

2, pp.356-357.
} 
En la segunda mitad del siglo, ese escenario cambió radicalmente. A los efectos de problematizar más claramente los distintos aspectos que involucraban el otorgamiento de la administración electoral al Poder Judicial, las discusiones fueron organizadas en temas y no cronológicamente.

\title{
a) El Poder Judicial como solución para los problemas del sufragio
}

El imponente y duradero rol electoral dado a los jueces de paz por el Decreto de Marzo 30 de 1830 pronto empezó a ser duramente criticado. La imagen común que entonces predominaba acerca de ese magistrado local está muy bien descrita por Aureliano Rodríguez Larreta59. En el Consejo de Estado, órgano creado luego de la disolución de las cámaras que siguió al golpe de estado presidencial de febrero de 1898, señaló:

\begin{abstract}
"En esta misma Cámara, señor presidente, hemos fulminado a los jueces de paz y a tal punto ha llegado la animadversión que les profesábamos como funcionarios electorales, que casi casi no se podía pronunciar el nombre juez de paz, sin que algún consejero se pusiera de pie, indignado, como si se pronunciara una mala palabra. [Risas]. Creíamos que los jueces de paz no servían para autorizar informaciones suplementarias del estado civil porque eran o habían sido agentes seguros de fraudes [...].”6o
\end{abstract}

Entre otras críticas, se entendía que en su papel de presidentes de las mesas inscriptoras no ofrecían garantías a los adversarios políticos y que podían ser “depositarios de las boletas fraudulentas". ${ }^{61}$ En el Consejo de Estado, en la discusión acerca de a quién correspondía la responsabilidad de la entrega de la boleta del votante, Justino Jiménez de Aréchaga ${ }^{62}$ defendió la postura de quitar a los jueces de paz esas funciones, "porque no tengo fe ninguna en la justicia que procedan al emitir boletas renovadas." Rodríguez Larreta le salió al cruce, afirmando que el fraude con los títulos lo podían cometer el juez de paz, el juez letrado, la Junta Electoral o cualquier otro funcionario. En su opinión, este aspecto era un punto mucho más

\footnotetext{
59 Miembro del partido Nacional; diputado por Montevideo (1888-1891; 1905-1908; 1920-1923; 19261929), Tacuarembó (1899-1901), Río Negro (1908-1911), Salto (1914-1917), San José (1917-1920) y Colonia (1923-1925); senador por Río Negro (1901-1904); consejero de Estado (1898). Parlamentarios..., o. cit., pp.19 y 1022.

6o Diario de Sesiones del Honorable Consejo de Estado, Montevideo, Imprenta Nacional, años indicados (De aquí en adelante CE), 26/o8/1898, tomo 2, p.407.

${ }^{61}$ Diario de Sesiones de la Honorable Cámara de Representantes, Montevideo, Imprenta El Siglo, años indicados (De aquí en adelante DR), 02/03/1893, tomo 126, pp.162-163. Intervención de Francisco Del Campo, Miembro del partido Nacional; diputado por Montevideo (1891-1894; 19021904; 1917-1920). Parlamentarios..., ob. cit., pp.19 у 506.

62 Diputado por Flores (1897); senador por Flores (1899-1901); consejero de Estado (1898). Parlamentarios..., ob. cit., pp.19 y 756.
} 
importante que el sistema electoral para la representación de las minorías, exigido por el Convenio de Paz de 1897 y entonces en discusión. ${ }^{63}$

En medio de esas discordancias, el Poder Judicial se presentaba como una posible solución a los problemas que afectaban a las elecciones uruguayas, principalmente debido a su presunta imparcialidad. En palabras del senador Martín Aguirre64:

"[L]os magistrados en su condición de miembros inamovibles de un poder desprovisto de fuerza y encargado de una misión social augusta, son los que tienen la presunción mayor de imparcialidad, condición esta que es la única necesaria e imprescindible [...] para los actos preparatorios de la elección"65

Posteriormente, el ministro del Gobierno Francisco Bauzá ${ }^{66}$ afirmó que la injerencia de los jueces letrados funcionaba como una garantía de la legalidad a los procedimientos electorales. ${ }^{67}$ Adolfo Pérez Olave ${ }^{68}$, al comentar sobre los recursos de inscripción, hizo una declaración similar:

"nuestra Ley electoral [...] establece esta clase de garantía en una forma tanto o más amplia, desde que va a entender en último término nada menos que uno de los altos Poderes del Estado: la Alta Corte, cuya rectitud, imparcialidad y espíritu de justicia está fuera de toda discusión". 69

En el mismo sentido indicaba Jacobo Varela Acevedo70: "es necesario que haya un Poder más amplio, más imparcial, más justo, en una palabra, que pronuncie la

${ }_{63}$ CE, 26/04/1898, tomo 1, pp.210-214. El Convenio de Paz de 1897 fue un acuerdo firmado entre el presidente Juan Lindolfo Cuestas y el partido Nacional después de la revolución comandada por Aparicio Saravia y Diego Lamas en 1897, motivada, entre otros aspectos, por disputas y garantías electorales. Consultar ACEVEDO, Eduardo, ob. cit., 1934, tomo 5, pp.12-23 y 115-118 y PIVEL DEVOTO, ob. cit., 1943, tomo 2, pp.379-391.

64 Miembro do partido Nacional; diputado por Canelones (1879-1882), Cerro Largo (1888-1891; 18971898), Rivera (1902-1905) y Colonia (1908); senador por Cerro Largo (1891-1897). Parlamentarios..., ob. cit., p.312.

65 Diario de Sesiones de la Honorable Cámara de Senadores, Montevideo, Imprenta Nacional, años indicados (De aquí en adelante DS), 01/o2/1893, tomo 58, pp.415-417.

66 Diputado por Montevideo (1876; 1888-1890), Soriano (1879-1881) y suplente por Montevideo (1886-1888); senador por Río Negro (1894-1898) y Soriano (1899); miembro del Consejo de Estado (1898). Parlamentarios..., ob. cit., pp.19 y 391-392.

${ }^{67} \mathrm{DS}, 01 / 07 / 1893$, tomo 58 , p.504.

68 Miembro del partido Colorado; diputado por San José (1905-1908) y Montevideo (1908-1909); senador por Durazno (1909-1915). Parlamentarios..., ob. cit., p.943.

69 DS, 08/27/1909, tomo 95, p.334.

70 Miembro del partido Colorado; diputado por Montevideo (1911-1913); senador por Rocha (19131919). BOTTINELLI, Oscar Alberto et. al. Enciclopedia Electoral del Uruguay (1900-2010), [s. l.], Instituto Factum - Jackson, Juan D., [s. f.], pp.45 y 5o. Parlamentarios..., ob. cit., p.1151. 
sentencia definitiva. Ese Poder no puede ser otro que el Judicial”. ${ }^{11}$ El senador también señaló que los jueces eran más capaces de entender y aplicar la ley:

\begin{abstract}
"Las corporaciones electorales, lo mismo que las Comisiones Calificadoras, están constituidas por ciudadanos que no tienen preparación especial en la materia de las leyes, $y$, en consecuencia, aun cuando procedan con la mejor buena fe, pueden incurrir en errores de interpretación que perjudiquen a los ciudadanos. Vuelvo a repetir que he tenido ocasión de comprobarlo con mucha frecuencia, cuando he tenido que intervenir en la revisión de procesos electorales. Las corporaciones referidas, procediendo con un espíritu generoso, no lo discuto, han incurrido, a mi juicio, muchas veces, en errores considerables. Hay necesidad, pues, de recurrir a una autoridad competente en derecho, que inspirando a todos, por su imparcialidad y por su capacidad, confianza completa, tenga la facultad de fallar de un modo definitivo".72
\end{abstract}

Como justificación para la implementación de la administración judicial de las elecciones, era también bastante común la mención a modelos extranjeros. Rosalío Rodríguez73, durante la discusión para la creación de Comisiones Extraordinarias para la depuración del Registro Cívico de Montevideo, enfatizó la importancia de las autoridades electorales en ese proceso y dio ejemplos de países en los cuales los jueces ya estaban integrados en la estructura electoral, como Bélgica, Italia e Inglaterra.74 En el Senado, Carlos A. Berro75 hizo lo mismo, agregando a Francia, España, Grecia y, con ciertas limitaciones, Suiza, Alemania y Austria. ${ }^{76}$ Juan Blengio Roca77 le contestó:

"El error fundamental del señor senador consiste en atribuir mayor autoridad moral a las decisiones de los tribunales electorales, constituidos por funcionarios administrativos,

\footnotetext{
${ }^{71}$ DS, 06/14/1915, tomo 107, p.515.

72 DS, 16/06/1915, tomo 107, p.524.

73 Miembro del partido Nacional; diputado por Montevideo (1902-1904; 1914-1917), Flores (1908-1911) y Colonia (1917-1919). Parlamentarios..., ob. cit., pp.152, 156, 159 y 162.

74 DR, 18/05/1909, tomo 199, p.234-237. Es importante señalar que Rodríguez defendía la presencia de autoridades permanentes en la administración del sufragio, que podrían ser miembros de cualquiera de los tres Poderes y no solamente del Judicial.

75 Miembro del partido Nacional; diputado por Minas (1888), Artigas (1897; 1926-1927), Rivera (18991902), Cerro Largo (1902-1904), Montevideo (1914-1919) y suplente por Paysandú (1924-1926); senador por Treinta y Tres (1891-1897) y Cerro Largo (1905-1911). Parlamentarios..., ob. cit., p.409.

${ }^{76}$ Otro indicio de ese intercambio internacional de ideas es la obra La représentation Proportionnelle: études de législation et de statistique comparées, organizada en 1888 por la Sociedad para el Estudio de la Representación Proporcional, con sede en Paris. Es una colección de once artículos sobre el funcionamiento de las elecciones en catorce países, que incluye el texto de Justino Jiménez de Aréchaga, también presente, con modificaciones, en la revista belga La représentation Proportionnelle y en su libro La Libertad Política. Consultar La représentation proportionnelle: études de législation et de statistique comparées, Paris, F. Pichon, 1888 y JIMÉNEZ DE ARECHAGA, Justino, La Libertad Política, Montevideo, Tipografía Escuela Nacional de Artes y Oficios, 1906, pp.343-362.

77 Miembro del partido Colorado; diputado por Montevideo (1899-1902) e Minas (1911); senador por Minas (1902-1908). Consultar Parlamentarios..., ob. cit., p.420.
} 
como lo establecen casi todas las legislaciones que ha citado el señor senador, en vez de tribunales constituidos por elementos procedentes de elección popular, como lo establece nuestra ley. En Francia, como en todos los demás países a que aludió el señor senador por Cerro Largo, los tribunales electorales constituidos por funcionarios o por corporaciones oficiales, adolecerán exactamente de los mismos vicios que el señor senador atribuye a los nuestros, porque siempre ocurrirá que esas corporaciones o esos funcionarios administrativos, convertidos por ministerio de la ley en tribunales de tachas, tendrán que resolver asuntos de orden electoral que afectan a sus adversarios políticos."78

\section{b) Los inconvenientes de la administración judicial de las elecciones}

Durante ese proceso de transformaciones, la administración electoral judicial trajo una serie de nuevos problemas al debate. Estaba, en primer plano, el temor de que la administración de la Justicia sufriera injerencias políticas; que los jueces al juzgar causas o al llevar a cabo los procedimientos de elección perdieran su imparcialidad. Para Francisco Del Campo, eran graves esos inconvenientes, ya que

"las contiendas siempre turbulentas, de la política, a cuyo calor se produce el apasionamiento, [...] colocarían a esos funcionarios en situación difícil, por no decir imposible, para responder dignamente y con imparcialidad necesaria, a los [...] cometidos inherentes a su cargo".79

Precisamente por esta razón, Duncan Stewart ${ }^{80}$ creía que los jueces letrados no debían intervenir en absoluto en la política. Aguirre no estaba de acuerdo y mencionó el caso de Argentina, donde la intervención de los jueces nacionales garantizaba, en su opinión, la imparcialidad de los Registros Cívicos. ${ }^{81}$ Otros como Antonio María Rodríguez $^{82}$ argumentaron que los tribunales no deberían tener competencia en la materia, a los efectos de evitar problemas en su funcionamiento regular. El diputado era partidario, sin embargo, de que la tuviera el juez letrado de primera instancia, ya que este sería el

\footnotetext{
${ }^{78} \mathrm{DS}, 27 / \mathrm{o8} / 1909$, tomo 95, pp. 315-320.

79 DR, 02/03/1893, tomo 126, p.168.

80 Diputado suplente por Montevideo (1895-1897); senador por Durazno (1889-1895) y Maldonado (1897-1898). Parlamentarios..., ob. cit., pp.1107-1108.

$81 \mathrm{DS}, 03 / 01 / 1893$, tomo 58, p.427.

82 Miembro del partido Colorado; diputado por Montevideo (1885-1898), Tacuarembó (1902-1908; 1911-1913) y San José (1908-1911); senador por Tacuarembó (1899-1901; 1913-1919); miembro del Consejo de Estado (1898). Parlamentarios..., ob. cit., pp.19 y 1011-1012.
} 
"funcionario más competente [...] para conocer, fuera de las probanzas y resultancias de autos, sobre las condiciones de los ciudadanos objeto de tachas, el que puede reunir [...] la prueba moral sobre la verdad o sobre la falsedad de esas tachas, sobre los móviles que actúan en esos casos". 83

La expansión de las funciones de los jueces para las diversas fases de las elecciones también se convirtió en un importante punto de debate. Comenzó a aparecer el miedo a la doble función del juez, lo que significaba que él iba a realizar procedimientos judiciales y administrativos relacionados con el voto, haciendo que se volviera, como indicó el senador Amaro Carve ${ }^{84}$, juez y parte al mismo tiempo.85 Sobre el tema habló Jiménez de Aréchaga, específicamente en lo que se refería al proceso de inscripción: "El sistema es malo, porque no puedo ver nunca un tribunal justo e imparcial el que esté compuesto, en gran parte, por individuos que han concurrido como inscriptores [...]; que van a ser más tarde materia de juicio en el jurado de tachas". ${ }^{86}$ La cuestión se hizo más controvertida en el debate de un proyecto para integrar jueces letrados a las Juntas Electorales. Algunos legisladores creían que la asistencia de los jueces podría aumentar las fuerzas de equilibrio en la Junta y que "por la naturaleza del cargo que desempeñaban y la imparcialidad de procederes que debía suponérseles, constituían una garantía para los partidos”.87 Para José Ladislao Terra ${ }^{88}$, un juez en un cuerpo de siete miembros no podía generar ningún problema, además de que su rol en la formación de las mesas sería remoto, porque solamente indicaría los miembros. ${ }^{89}$ Otros parlamentarios no estaban de acuerdo con la idea. Para Amaro Carve, por ejemplo, dicha intervención sería, en sus palabras, inconveniente, impolítica y peligrosa. Finalmente, a propuesta del senador Alcides Montero ${ }^{90}$, la presencia del magistrado en la Junta fue eliminada. ${ }^{91}$

Teniendo en cuenta esos posibles problemas de acercamiento entre la Judicatura y las elecciones, se hicieron propuestas para eliminarlos o al menos intentar

\footnotetext{
83 DR, 03/15/1893, tomo 126, pp.377-379.

84 Diputado suplente por Montevideo (1870-1873); senador por Durazno (1874-1876) y Soriano (18891895). Parlamentarios..., ob. cit., pp.19 y 480.

85 DS, 29/12/1892, tomo 58 , p.342.

${ }^{86} \mathrm{CE}, 08 / 22 / 1898$, tomo 2 , p.368,

${ }_{87}$ DR, 03/o8/1893, tomo 126, p.285. Intervención del diputado Antonio M. Rodríguez.

88 Diputado por Montevideo (1879-1882); senador por Paysandú (1889-1895), Colonia (1899-1902) y suplente por Artigas (1897-1898). Parlamentarios..., ob. cit., pp.19 y 1123-1124.

89 DS, 03/01/1893, tomo 58, pp.424-425.

90 Diputado por Montevideo (1879-1882), Flores (1897-1898) y suplente por Colonia (1891-1892); senador por Flores (1892-1897). Parlamentarios..., ob. cit., pp.19 y 855.

${ }_{91}$ DIEZ DE MEDINA, Álvaro, ob. cit., pp.331-332 y 336.
} 
reducirlos. Una de las más mencionadas fue plantear la incompatibilidad, mecanismo previsto desde 1826, que prohibía la elección de personas que ocupaban determinados cargos..$^{2}$ Ese tipo de medida pasaba por la suposición de que podría haber una influencia de un funcionario del Gobierno para ser elegido al Parlamento. No obstante, no todos pensaban así. El senador Carve se preguntaba:

"Dos funcionarios que han administrado debidamente el departamento que han tenido a su cargo, uno político y otro judicialmente; ¿no tienen el derecho de ser recompensados por los sacrificios patrióticos que han hecho [...], de ser premiados por haber procedido honrada y rectamente?"93

José P. Espalter94 dijo que era muy común en América del Sur que los jueces fueran también legisladores.95 Jiménez de Aréchaga era también contrario a la incompatibilidad de los jueces, porque la Constitución de 1830 no la determinaba: "toda ley o toda disposición legal que tienda a restringir el ejercicio de un derecho civil o político, son disposiciones de carácter odioso, que no pueden extenderse sino a lo que expresamente en ellas se ha establecido". ${ }^{96}$

Gonzalo Ramírez ${ }^{97}$ no estaba de acuerdo con su colega consejero, ya que la situación política del juez departamental había cambiado a partir del establecimiento de sus nuevas funciones electorales. ${ }^{8}$ Del mismo modo, el ministro del Gobierno defendió la incompatibilidad absoluta de los jueces letrados y jefes políticos, pues, según pensaba, sería fácil que ellos llegaran a un acuerdo para elegirse.99

En paralelo a esa solución aportada por la incompatibilidad, había quienes defendían formas más participativas de gestión electoral. Estas, de hecho, nunca

${ }_{92} \mathrm{El}$ decreto de 19 de enero de 1826 y la Constitución de 1830 (artículos 25 y 31) prohibía la elección de ciertos individuos, especialmente de la esfera del Poder Ejecutivo, a la Cámara de Representantes y al Senado. Para el Poder Judicial, esa restricción fue establecida por la ley $n^{0} 728 / 1862$, revocada por la ley $\mathrm{n}^{\circ}$ 906/1867 durante el Gobierno Provisorio de Venancio Flores. En 1893, la ley no 2.224 (artículos 34 y 46) estableció la incompatibilidad relativa de los jueces letrados, jefes políticos y agentes fiscales, para el departamento en que hayan sido electos o habían ejercido el cargo en los seis meses anteriores, mantenida por la ley $\mathrm{n}^{\circ}$ 2.563/1898 (artículos 34 y 46). La Constitución de 1918 (artículos 23 y 30), finalmente, reafirmó la incompatibilidad relativa de la Judicatura.

$93 \mathrm{DS}, 01 / 07 / 1893$, tomo 58 , p. 516.

94 Miembro del partido Colorado y del Colorado Radical; diputado por Rocha (1897-1902; 1917-1919), Paysandú (1902-1903) y Montevideo, como titular (1926-1929) y suplente (1929); senador por Durazno (1905-1909), Maldonado (1911-1915), Rocha (1919-1925) y nacional (1934-1940) ; miembro del Consejo de Estado (1898). Parlamentarios..., ob. cit., p.19, p.592.

$95 \mathrm{CE}, 01 / 07 / 1898$, tomo 2, p.110.

${ }_{96} \mathrm{CE}, 06 / 27 / 1898$, tomo 2, p.85.

97 Consejero de Estado (1898). Parlamentarios..., ob. cit., p.19.

${ }^{98} \mathrm{CE}, 06 / 27 / 1898$, tomo 2, pp.91-92.

99 DS, 01/10/1893, tomo 59, p.31. 
habían sido totalmente abandonadas, pero pasaron por cambios importantes en el período. El juez de paz, prácticamente sin ninguna actuación electoral desde 1878, había sido sustituido en gran medida por las Juntas Económico-Administrativas y posteriormente por las Juntas Electorales. Además de los órganos electivos, participaban también directamente en la gestión electoral los ciudadanos, indicados o sacados a suerte. En este sentido, Manuel B. Otero ${ }^{100}$ defendió la validación de las elecciones del Parlamento por sus propios miembros:

\footnotetext{
"Nuestros constituyentes aspiraron a los juicios por jurados, en materia criminal; a los juicios por jurados en materia civil. Consideraron que el pueblo era el gran juez, el que ofrecía las mayores garantías. El tribunal popular en materia política no es más que simple aplicación del mismo principio general”. ${ }^{101}$
}

Para otros, la función electoral podría hacer mal al ejercicio de un cargo que desempeñara distintas tareas, como se discutió con respecto a los jueces letrados. José Ladislao Terra pensaba de esa manera en el caso de los jueces de paz, que eran elegidos y tenían jurisdicción en otras áreas. Así, en las elecciones para jueces de paz, podrían ser electos hombres de partido, que no harían buenos jueces, según opinaba.102 El mismo argumento podría ser aplicado a las Juntas EconómicoAdministrativas, pero no tanto a las Juntas Electorales, debido a su especialización. Así parecía reconocer el senador Carlos Berro: "Las Juntas Electorales, como es sabido, son, en nuestro sistema eleccionario, autoridades que tienen a su cargo la dirección, casi exclusiva, del ejercicio del derecho electoral”. ${ }^{103}$ Y es importante acordarse que, a pesar de la creciente presencia del juez en la gestión electoral uruguaya, ello no significó la eliminación de las Juntas Electorales. Incluso la Reforma de 1924 que creó la Corte Electoral mantuvo esos órganos, aunque con una ligera reducción de sus funciones.104 La comisión que presentó el proyecto de ley justificó la permanencia de las Juntas debido a su larga presencia en la vida electoral del país, conservando su forma de composición electiva. Sobre este aspecto también hicieron una comparación entre las Juntas y la Corte Electoral que se creaba:

\footnotetext{
100 Miembro do partido Colorado; diputado por Salto (1888-1891), Montevideo (1905-1908) y Maldonado (1914-1915); senador por Artigas (1909-1915) y Montevideo (1917-1923). Parlamentarios..., ob. cit., p.902.

${ }_{101} \mathrm{DS}, 08 / 27 / 1909$, tomo 95, p.327.

102 DS, 01/o5/1893, tomo 58, pp.462-463.

103 DS, 09/10/1907, tomo 91, pp.124-125.

104 SOUZA, Alexandre de Oliveira Bazilio de, Las Juntas Electorales en Uruguay, Ponencia en VI Jornadas Nacionales y II Internacionales sobre el siglo XIX “Doscientos años independientes”, Mar del Plata, 2016.
} 
"las Juntas Electorales, emanación directa de la voluntad popular, serán los jueces primarios [...]. La Corte Electoral, entidad suprema del organismo electoral, rodeada de garantías de origen, de estructura, de funcionalidad y de responsabilidad tales que aseguren la imparcialidad de sus fallos, será el juez de segunda y última instancia [...]”. ${ }^{105}$

\section{c) Lo político versus lo jurídico}

La cita anterior de la Comisión que analizó el proyecto de creación de la Corte Electoral es interesante. A pesar de la distinción que se hace entre los orígenes jurídicos y políticos de la Corte y de las Juntas Electorales respectivamente, se reconoció que sus papeles no eran necesariamente tan distintos, ya que los dos fueron denominados jueces. De hecho, esa falta de distinción aparece muy a menudo en los anales consultados. Berro, por ejemplo, comparó las Juntas con tribunales, en tanto juzgaban recursos interpuestos ante las resoluciones de las Comisiones Inscriptoras, Receptoras y Escrutadoras. ${ }^{106}$ Alfredo Vásquez Acevedo ${ }^{107}$ también tenía este punto de vista y las llamaba verdaderos tribunales. ${ }^{108}$ Para José Espalter: "las funciones del poder electoral, por la serenidad de criterio que requieren y por la imparcialidad que necesitan, son completamente análogas a las funciones, delicadas e importantes, que desempeñan los magistrados del Poder Judicial”.109 Y para Jiménez de Aréchaga: “Las atribuciones de las Juntas Electorales y las Comisiones Inscriptoras tiene mucha analogía con las atribuciones del juez; [pero] él es el único responsable de lo que hace al aplicar bien o mal la disposición legal”. ${ }^{110}$

En otras ocasiones, las Juntas eran descritas como cuerpos eminentemente políticos. Cuando se discutía la representación proporcional en su elección, Julio María Sosa111 dijo: "yo creo que en una Junta Electoral, que es una corporación

\footnotetext{
105 DR, 22/11/1923, tomo 312, pp.36-42.

${ }^{106}$ DS 09/10/1907, tomo 91, p.125.

107 Miembro del partido Nacional; diputado por Montevideo (1905-1908; 1914-1917); senador por Flores (1901-1904) y San José (1917-1919); miembro del Consejo Nacional de Administración. BOTTINELLI, Oscar Alberto et. al. ob. cit., pp.12, 25, 55 y 76. Parlamentarios..., ob. cit., p.1157. 108 DIEZ DE MEDINA, Álvaro, ob. cit., p.505.

109 CE, 02/05/1898, tomo 1, p.416.

${ }^{110}$ CE, 06/07/1898, tomo 2, p.128. Es importante tener en cuenta que, para Jiménez de Aréchaga, fue la ley que dio funciones judiciales (o análogas a ellas) a las Juntas Electorales, pero ello no significaba que estas podían ser denominadas tribunales. Consultar CE, 03/10/1898, tomo 3, p.328.

${ }_{111}$ Miembro del partido Colorado; diputado por Maldonado (1905-1915; 1920-1923); senador por Artigas (1917-1920). Parlamentarios..., ob. cit., p.1108.
} 
política, deben estar representadas todas las fuerzas populares".112 Julio Grauert113 fue aún más enfático en ese punto:

\begin{abstract}
"Es una doctrina errónea la de querer suponer que las Juntas Electorales deben ser consideradas como organismos o entidades ajenas a las fracciones políticas; en esto hay un doble error. Si las Juntas Electorales, se dice que son tribunales a los efectos de que apliquen debidamente la ley, es indudable que entonces serían tribunales; pero, si se quiere hacer de las Juntas Electorales corporaciones ajenas a las fracciones políticas de nuestro país, me parece que es algo utópico, algo simplemente imposible”. ${ }^{114}$
\end{abstract}

Al revisar la legislación es bastante complicado definir exactamente lo que constituye el carácter político o jurídico de estos órganos, basados específicamente en el rol que jugaron. Todos tenían la ley como soporte fundamental, realizaban la subsunción del hecho a la norma en procesos que tenían distintas instancias. Del mismo modo, los dos eran órganos electivos, externos a los Poderes constituidos y de cuyos miembros no se exigía la formación en Derecho. ${ }^{115}$ Pero en términos de imagen, la Corte Electoral estaba mucho más asociada a una función jurídica por los parlamentarios en comparación con las Juntas, y tal vez por ello fue ubicada en el puesto más alto de la estructura electoral.

Por fin, es importante señalar que esas discusiones muestran que la defensa y el rechazo a la administración judicial de las elecciones no tenían relación directa con la estructura partidaria. Al analizar la filiación de los políticos mencionados, hay adeptos de ambas corrientes en los dos partidos tradicionales del país. En favor, estaban Adolfo Pérez Olave, Jacobo Varela Acevedo y Antonio María Rodríguez, del partido Colorado, y Martín Aguirre, Carlos A. Berro, Rosalío Rodríguez, del partido Nacional. En contra estaban Blengio Roca, del partido Colorado y Aureliano Rodríguez Larreta y Francisco Del Campo, del partido Nacional. Son datos puntuales, pero que demuestran que la gestión judicial del sufragio no era proyecto de un partido y su concreción debe ser analizada desde otra perspectiva, que incluye entender la imagen que se atribuía al Poder Judicial, no sólo en Uruguay sino en muchos países.

\footnotetext{
${ }_{112}$ DR, 27/08/1907, tomo 192, p. 127.

${ }_{113}$ Miembro del Partido Colorado; diputado suplente por Montevideo (1909-1910). Parlamentarios..., ob. cit., p.704.

114 DR, 07/10/1909, tomo 201, p.519.

${ }^{115}$ Los miembros de los Poderes Ejecutivo, Legislativo y Judicial no podían formar parte de la Corte Electoral ni de las Juntas Electorales, según la ley nº 7.690/1924 (artículos 11 y 27).
} 


\section{Conclusión}

A lo largo de este trabajo se vio que los jueces estuvieron presentes en la administración electoral uruguaya por un largo período, hasta el establecimiento de la Corte Electoral en 1924. Hay, no obstante, una cierta supervaloración de ese nuevo escenario resultado, en mi opinión, de toda la red de argumentos puestos por los contemporáneos para justificar esas reformas, muchos de los cuales fueron después repetidos acríticamente por la historiografía.

Entre esos argumentos, el fraude seguramente era central. No propuse acá estudiar ese fenómeno en el plano de la práctica -o sea, analizar si los jueces eran más o menos corruptos en comparación con otros gestores -, sino mostrar cómo ese y otros argumentos fueron fundamentales para elegir a la Judicatura como el principal administrador del sufragio en el país. Como consecuencia, hubo un cambio vital en la construcción de la ciudadanía uruguaya en el período, ya que se volvió menos deseable que autoridades electivas y legas formaran parte de la estructura electoral, mientras se valoraba la gestión técnica de los jueces.

Por otro lado, ese movimiento en Uruguay, en comparación a otros países, no fue tan intenso, en la medida que en este país las Juntas Electorales -órganos electivos- fueron mantenidas. Asimismo, los miembros de la Corte Electoral también eran electos, aunque de forma indirecta, y de ellos no se exigía la formación en Derecho. Era el reconocimiento de que la Magistratura Letrada tal vez no fuera la solución definitiva a los problemas que afectaban al sufragio; o el resultado del miedo que los contemporáneos tenían al involucramiento de lo jurídico con lo político.

\section{Fuentes y bibliografía}

\section{Fuentes}

ARMAND UGÓN, E. et al, Compilación de Leyes y Decretos (1825-1930), Montevideo, 1930, varios tomos.

Diario de Sesiones de la Honorable Asamblea General, Montevideo, Imprenta El Laurak-Bat, años indicados [AG].

Diario de Sesiones de la Honorable Cámara de Representantes, Montevideo, Imprenta El Siglo, años indicados [DR]. 
Diario de Sesiones de la Honorable Cámara de Senadores, Montevideo, Imprenta Nacional, años indicados [DS].

Diario de Sesiones del Honorable Consejo de Estado, Montevideo, Imprenta Nacional, años indicados [CE].

JIMÉNEZ DE ARÉCHAGA, Justino, La Libertad Política, Montevideo, Tipografía Escuela Nacional de Artes y Oficios, 1906.

La représentation proportionnelle. Études de législation et de statistique comparées, Paris, F. Pichon, 1888.

\section{Bibliografía de apoyo}

ACEVEDO, Eduardo, Anales Históricos del Uruguay, 6 tomos, Montevideo, Barreiro y Ramos, 1933-1936.

ANNINO, Antonio, "Introducción", A. ANNINO, Historia de las elecciones en Iberoamérica. Siglo XIX, Buenos Aires, Fondo de Cultura Económica, 1995.

ANNINO, Antonio, "El voto y el XIX desconocido”, Istor, núm. 17, 2004, pp.43-59.

BARRAN, José Pedro, NAHUM, Benjamín, Batlle, los Estancieros y el Imperio Británico. La derrota del Batllismo (1916), Tomo 8, Montevideo, Ediciones de la Banda Oriental, 1987.

BOTTINELLI, Oscar Alberto et al. Enciclopedia Electoral del Uruguay (19oo-2010). [s. 1.]: Instituto Factum - Jackson, Juan D., [s. f.].

BRAGONI, Beatriz, "Los avatares de la representación. Sufragio, política y elecciones en Mendoza, 1854-1881", Hilda SABATO y Alberto LETTIERI (comp.), La vida política en la Argentina del siglo XIX. Armas, votos y voces, Buenos Aires, Fondo de Cultura Económica, 2003.

CAETANO, Gerardo, La República Batllista, Montevideo, Ediciones de la Banda Oriental, 2011.

Cámara de Representantes, Tablas Cronológicas (1830-1971), Montevideo, Sección "Información y antecedentes legislativos", 1971.

CARVALHO, José Murilo de, “Cidadania: tipos e percursos”, Estudos Históricos, Rio de Janeiro, núm. 18, 1996, pp.338-359.

CABRAL, João Crisóstomo da Rocha, Sistemas eleitorais do ponto de vista da representação proporcional das minorias, Rio de Janeiro, Livraria Francisco Alves, 1929.

CUADRO CAWEN, Inés, "Partidos, elecciones y democracia política”, Ana FREGA et al., Historia del Uruguay en el siglo XX (1890-2005), Montevideo, Ediciones de la Banda Oriental, 2007, pp.317-357.

CUADRO CAWEN, Inés, "La crisis de los poderes locales. La construcción de una nueva estructura de poder institucional en la Provincia Oriental durante la guerra de independencia contra el Imperio del Brasil (1825-1828)", Ana FREGA, Historia Regional e Independencia del Uruguay. Proceso histórico y revisión crítica de sus relatos, Montevideo, Ediciones de la Banda Oriental, 2009, pp.65-100. 
DE LOS SANTOS, Clarel, De la soberanía provincial a la facción gobernante. Experiencias electorales en Villa San Juan Bautista-Canelones (1825-1838), Ponencia en VI Jornadas Académicas de la Facultad de Humanidades y Ciencias de la Educación, Montevideo, 2015.

DIEZ DE MEDINA, Álvaro, El voto que el alma pronuncia. Historia Electoral del Uruguay (1810-1910), Montevideo, Fundación de Cultura Universitaria / Fundación Banco de Boston, 1994.

GALLO, Ezequiel, "Prólogo”, Fernando J. DEVOTO, Marcela P. FERRARI (comp.), La Construcción de las Democracias Rioplatenses. Proyectos institucionales y prácticas políticas (1900-1930), Buenos Aires, Biblos, 1994.

GONZÁLEZ, Rodolfo, Legislación Electoral del Uruguay, [s.l.], Celadu, 1991.

GROS ESPIELL, Héctor, La Corte Electoral del Uruguay, San José, CAPEL, 1990.

GROS ESPIELL, Héctor, ARTEAGA, Juan José, Esquema de la Evolución Constitucional del Uruguay, Montevideo, Fundación de Cultura Universitaria, 1991.

LINDAHL, Göran, Batlle. Fundador de la democracia en el Uruguay, Montevideo, Editorial Arca, 1960.

MARSHALL, T. H., Ciudadanía y Clase Social, Madrid, Alianza, 1998.

Parlamentarios Uruguayos, [s.l.], Presidencia de la Asamblea General y del Senado, Presidencia de la Cámara de Representantes, 2006.

OROZCO HENRIQUEZ, J. Jesús, "El contencioso electoral, la calificación electoral”, Dieter NOHLEN et al, Tratado de derecho electoral comparado de América Latina, México, Fondo de Cultura Económica, 2007.

PIVEL DEVOTO, Juan, Historia de los Partidos Políticos en el Uruguay, Montevideo, Claudio García \& Cía., 1942-1943, 2 tomos.

PIVEL DEVOTO, Juan E., RANIERI DE PIVEL, Alcira, Historia de la República Oriental del Uruguay (1830-1930), Montevideo, Medina, 1966.

POSADA-CARBÓ, Eduardo, "Elections before Democracy. Some considerations on electoral history from a comparative approach", E. POSADA-CARBÓ, Elections before Democracy. The history of elections in Europe and Latin America, Houndmills, Macmillan Press Ltd, 1996.

ROMANELLI, Raffaele, "Sistemas electorales y estructuras sociales. El siglo XIX europeo”, Salvador FORNER (coord.), Democracia, elecciones $y$ modernización en Europa: Siglos XIX y XX, Madrid, Cátedra, 1997.

SABATO, Hilda, La política en las calles. Entre el voto y la movilización (Buenos Aires, 1862-1880), Buenos Aires, Sudamericana, 1998.

SABATO, Hilda, "Introducción”, Hilda SABATO, (coord.), Ciudadanía Política y Formación de las Naciones. Perspectivas históricas de América Latina, México, Fondo de Cultura Económica, 1999.

SÁNCHEZ GÓMEZ, Gonzalo, "Ciudadanía sin democracia o con democracia virtual”, Hilda SABATO, (coord.), Ciudadanía política y formación de las naciones. Perspectivas históricas de América Latina, México, FCE, 1999. 
SOUZA, Alexandre de Oliveira Bazilio de, Das urnas para as urnas: juízes de paz e eleições no Espírito Santo (1871-1889), Saarbrücken, Novas Edições Acadêmicas, 2013.

SOUZA, Alexandre de Oliveira Bazilio de, Las Juntas Electorales en Uruguay, VI Jornadas Nacionales y II Internacionales sobre el siglo XIX “Doscientos años independientes" [presentación oral], Mar del Plata, 2016.

VANGER, Milton I, José Batlle y Ordóñez (1915-1917). Humanizando el capitalismo, Montevideo, Ediciones de la Banda Oriental, 2009.

TERNAVASIO, Marcela, La Revolución del Voto. Política y Elecciones en Buenos Aires (1810-1852), Buenos Aires, Siglo XXI, 2002.

TURNER, Bryan Stanley, "Outline of a theory of citizenship”, Sociology, vol. 24, núm. 2, 1990, pp.189-217.

ZUBILlaGA, Carlos, "El difícil camino de la participación política. Población, ciudadanía y electorado (1898-1918)", Fernando J. DEVOTO, Marcela P. FERRARI (comp.), La Construcción de las Democracias Rioplatenses. Proyectos institucionales y prácticas políticas (1900-1930), Buenos Aires, Biblos, 1994. 